\title{
MEDICAL AND SOCIAL IMPLICATIONS OF TEENAGE PREGNANCY
}

\author{
Marioara Boia ${ }^{1,2}$, E.S. Boia ${ }^{1}$, Daniela Cioboata ${ }^{2}$, Aniko Manea ${ }^{1,2}$ \\ 1 "Victor Babes" University of Medicine and Pharmacy, Timisoara \\ 2 "Louis Turcanu” Children's Emergency Hospital, Timisoara
}

\begin{abstract}
Pregnancy in adolescence is a special situation, especially among teenagers who do not benefit from family support, being at risk of not receiving adequate prenatal care during pregnancy, of having complications during pregnancy and birth for the mother and especially for the newborn.

Aim. The purpose of this paper is to present the pathology and complications associated to the newborn of teenage mothers.

Material and method. Retrospective study of patients hospitalized during January 2013 - December 2014, the study inclusion criteria being maternal age up to 17 years.

Results. $66.67 \%$ of the newborn in the study were preterm babies and $33.33 \%$ were newborn at term. Postpartum complications were more frequent and severe in the preterm newborns versus the newborn at term group. Correlating data about pathology, gestational age and birth weight with biological age of the mother reveals that mothers aged 13-15 years gave birth mostly to premature newborn as opposed to mothers aged 16 to 17 years. Mothers of preterm newborn that had extremely low and low birth weight were aged between 13-15 years.

Conclusions. Pregnancy in adolescence is associated most frequently with giving birth to preterm newborn. The lower the biological age of the mother is, the higher the risk of a premature birth, the more severe complications being associated with lower gestational age and lower birth weight of the premature baby.
\end{abstract}

Keywords: prematurity, pregnancy in adolescence, teenage mothers

\section{INTRODUCTION}

Teenage pregnancy is one of the current public health problems today, being a widespread phenomenon both globally and nationally. In 2014 the World Health statistics indicated that in the world, the rate of births given by girls between the ages of 15 and 19 years was 49 per 1,000 live births. Teen pregnancy is not only a social issue but rather a medical one. Teenage mothers are a group of patients with high risk for complication prone pregnancies and childbirths and associated increased risk of complications to the fetus and newborn.

Common complications of pregnancy in adolescence are represented by prematurity and intrauterine growth restriction. Risk factors associated with these complications are both biological/medical in nature (incomplete maternal stature development, poor nutrition of the mother, sexually transmitted infections, absence or insufficient prenatal care) and also socio-economic in nature (tobacco, alcohol, drugs consumption during pregnancy, low education level or school dropout, low socioeconomic status) (5).

Prematurity and intrauterine growth restrictions are associated with increased neonatal morbidity and mortality. This paper aims to present the complications associated with teenage pregnancy, prematurity taking away a major role in determining the perinatal morbidity and mortality.

\section{MATERIAL AND METHOD}

A retrospective study was conducted, covering the period January $1^{\text {st }} 2013$ to December $31^{\text {st }} 2014$, assessing data from patients hospitalized in the Neonatal and Premature ward of the Clinical Emer- 
gency Hospital for Children "Louis Turcanu" Timisoara. The inclusion criterion was the mother biological age up to 17 years. The cases where we did not have data on the biological age of the mother were excluded from the study. Data were obtained from patient observation sheets, including information on maternal age, the mothers' environment, the degree of hospitalization of pregnancy, the gestational age of the newborn, birth weight and associated pathology of the newborn.

According to the World Health Organization preterm infants are infants born before 37 weeks. LBW (low birth weight) are newborn babies with birth weight (BW) less than 2,500 g, VLBW (very low birth weight) are those with BW less than 1,500 $\mathrm{g}$ and ELBW (extreme low birth weight) are those with BW less than $1,000 \mathrm{~g}$. Intrauterine growth restriction (IGR) or small for gestational age (SGA) is defined when the newborn is with BW below the $10^{\text {th }}$ percentile for gestational age and sex. Newborn at term and normal weight baby is defined as newborn baby with gestational age of 38-42 weeks and $\mathrm{BW}$ of 2,500-4,000 g (12).

\section{RESULTS}

Of the total 1,399 admissions made during 20132014,39 patients were included in the study, representing $2.78 \%$ of total admissions.

Patient distribution by biological age of the mother shows that the groups with the most mothers were that of 16 year old patients (46.15\%) and that of 17 years old mothers $(30.77 \%)$ respectively (Table 1$)$.

We divided the group according to gestational age into two groups: preterm newborns and at term.

In relation to gestational age, the highest frequency were premature newborn - 26 (66.67\%) and of these, according to $\mathrm{BW}$, the most frequent were LBW - 16 (41.03\%), (Fig. 1).
TABLE 1. Patient distribution of biological age of the mother

\begin{tabular}{|c|c|c|}
\hline Biological age & Frequency & Percentage \\
\hline 13 years & 2 & 5.13 \\
\hline 14 years & 2 & 5.13 \\
\hline 15 years & 5 & 12.82 \\
\hline 16 years & 18 & 46.15 \\
\hline 17 years & 12 & 30.77 \\
\hline Total & 39 & 100 \\
\hline
\end{tabular}

Regarding the degree of hospitalization of pregnancy, the more frequent were patients with nonhospitalized pregnancies (24-61.54\%) compared with those whose pregnancies were hospitalized (15-38.46\%). It was noted that the ratio of newborn babies coming from hospitalized pregnancies was approximately equal to 8 preterm newborn to 7 at term. The ratio of newborn from non-hospitalized pregnancies was of many preterm newborn to a few on term ones (Fig. 2).

Postpartum complications of newborn were more frequent in the group of infants born preterm compared to those born at term. Neurologically speaking, premature infants had brain hemorrhage more frequently, while at term newborn infants had developed hypoxic ischemic encephalopathy (HIE) (Fig. 3).

Analyzing separately the two groups of newborn, it was observed that the severe perinatal complications were in the preterm group, prematurity itself having a role in determining perinatal morbidity. Among these, the most affected were infants with BW extremely low and very low (ELBW and VLBW). Neonatal respiratory distress, early complication of prematurity was present in 9 cases, 4 of them requiring mechanical ventilation support: 2 being premature ELBW and 2 VLBW. Another complication of prematurity is retinopathy of prematurity, which was present in 10 cases. Of these,

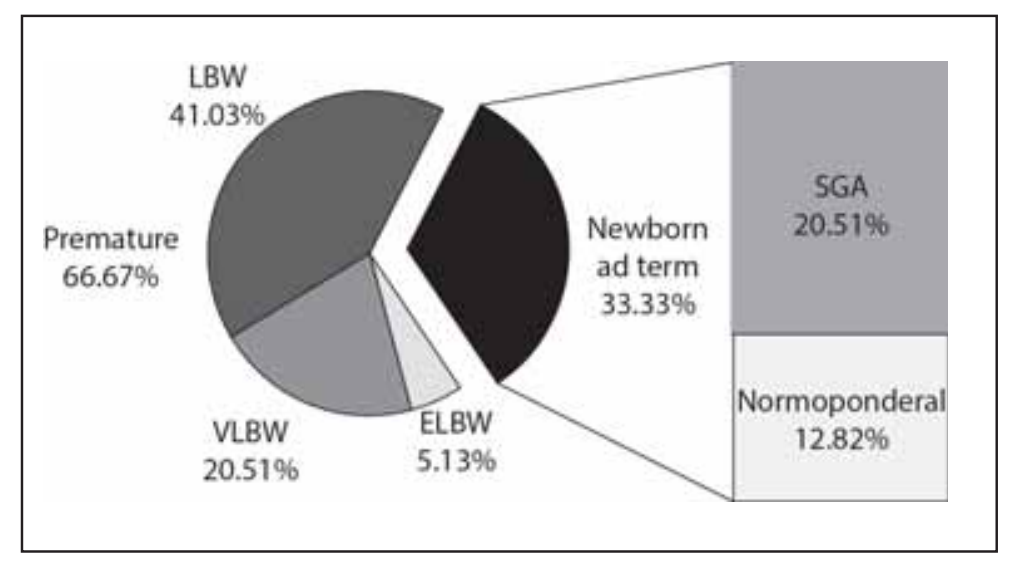

FIGURE 1. Patient distribution by birth weight and gestational age 


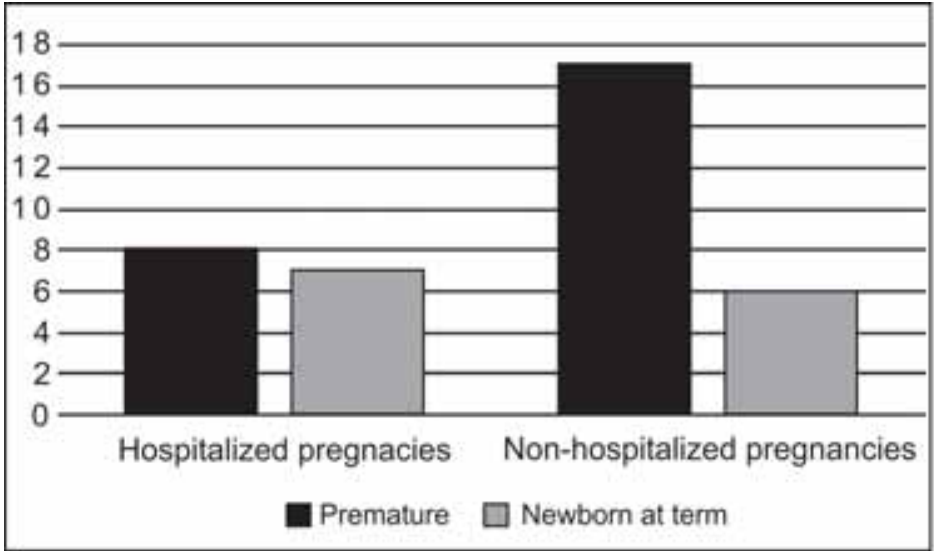

FIGURE 2. Distribution of pregnancies depending on the degree of hospitalization

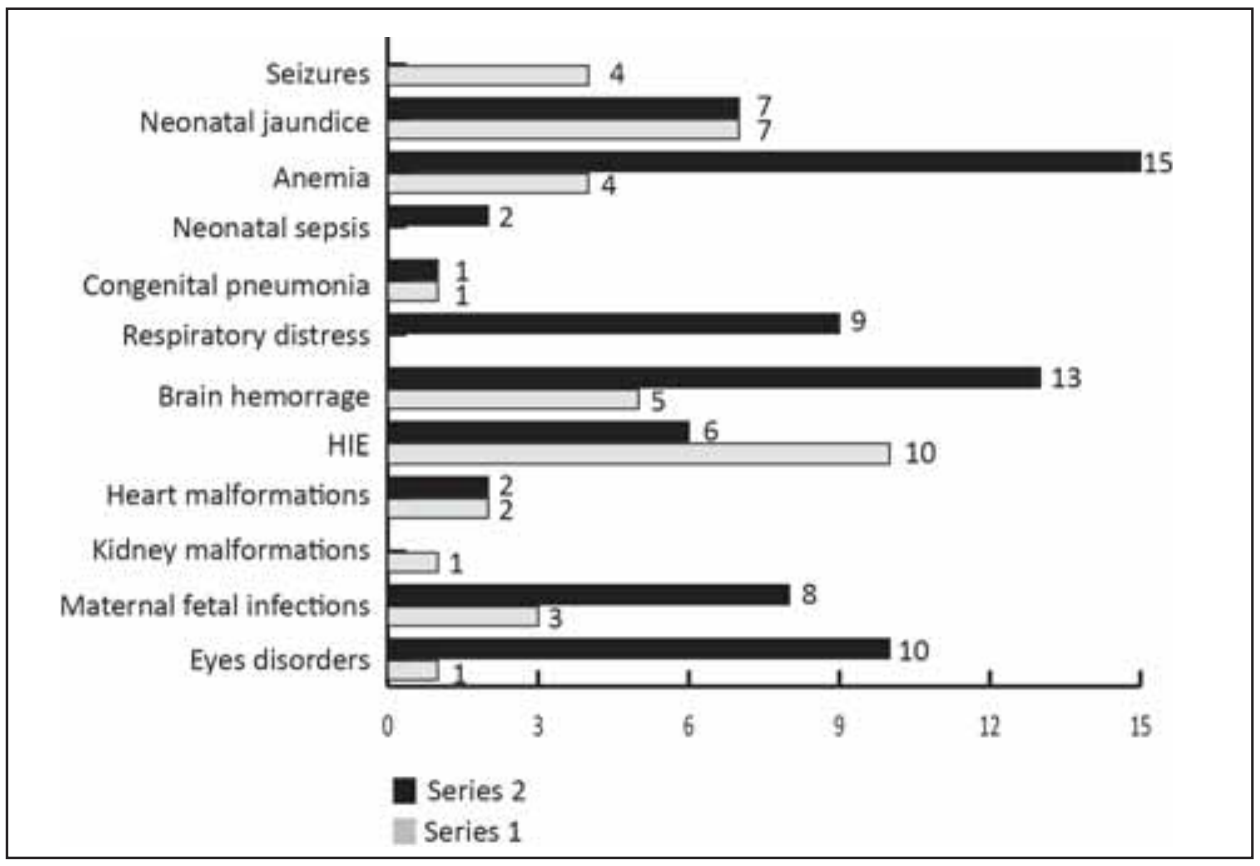

FIGURA 3. Postpartum complications of newborn

four required laser ablation, but the evolution was unfavorable in 3 cases with retinal detachment, particularly those with extremely low BW - Fig. 3.
In the on term newborn group, the most frequent newborn complications were shown by those with SGA, compared to normal weight babies, a

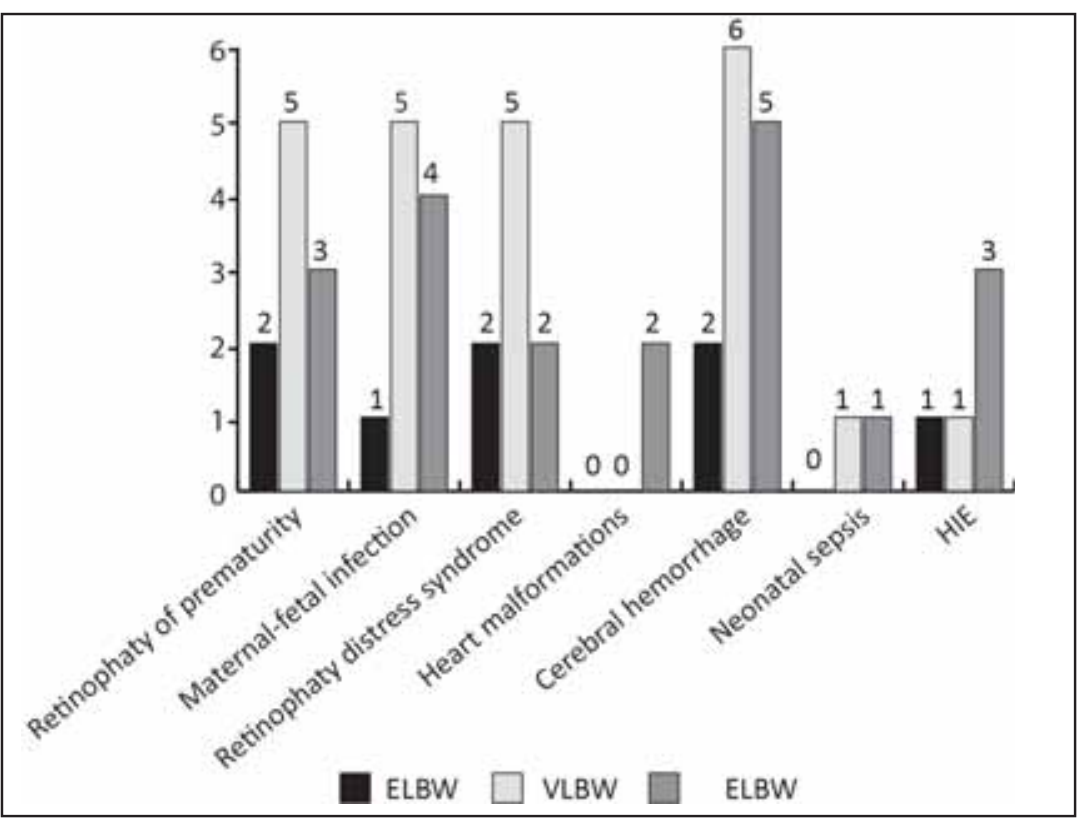


single case presenting eye disease - optic atrophy and one case showed congenital pneumonia, requiring mechanical ventilation support (Fig. 4).

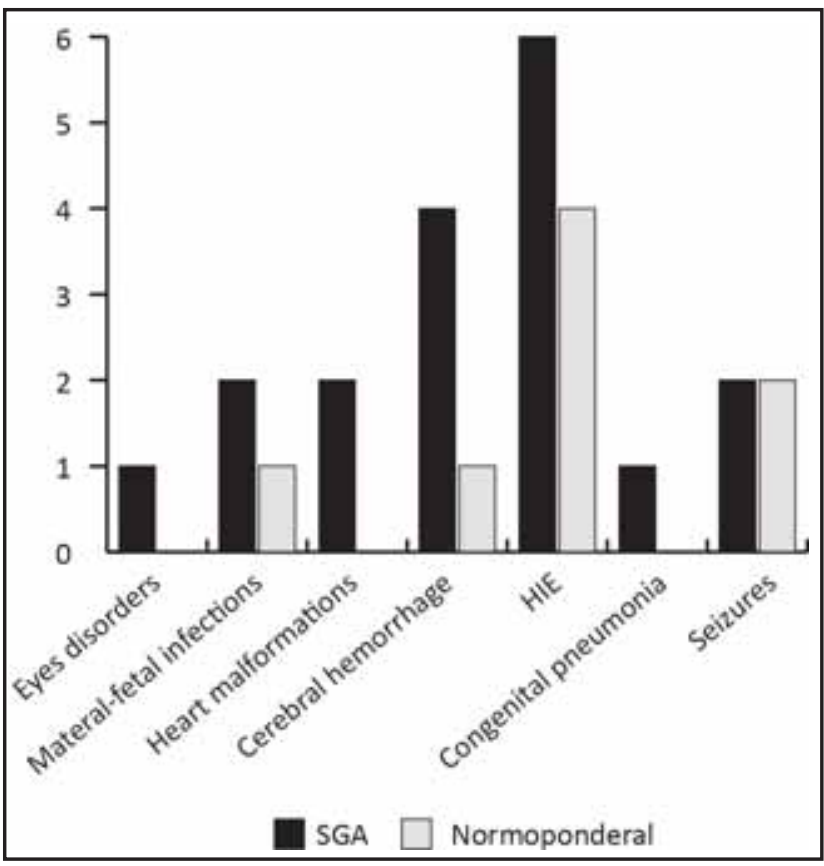

FIGURE 5. Postpartum complications of newborns at term

Correlating data about pathology, gestational age and birth weight of the studied cases with the biological age of the mother, revealed that mothers aged between 13 and 15 years gave birth mostly to premature babies, compared to mothers aged 16 to 17 years. Mothers of newborn with extremely low BW and very low BW were aged between 13 and 15 years (Table 2).

TABLE 2. Distribution of newborn infants according to gestational age, birth weight and maternal biological age

\begin{tabular}{|l|c|c|c|c|c|}
\hline \multirow{2}{*}{$\begin{array}{l}\text { Mother's } \\
\text { biological } \\
\text { age }\end{array}$} & \multicolumn{3}{|c|}{$\begin{array}{c}\text { Premature newborn } \\
(\mathbf{n = 2 6 )} \mathbf{n}(\%)\end{array}$} & \multicolumn{2}{c|}{$\begin{array}{c}\text { Newborn at term } \\
(\mathbf{n}=13) \mathbf{n}(\%)\end{array}$} \\
\cline { 2 - 6 } & ELBW & VLBW & LBW & SGA & $\begin{array}{c}\text { Normo- } \\
\text { ponderal }\end{array}$ \\
\hline $13-15$ years & $2(5.13)$ & $3(7.70)$ & $3(7.70)$ & - & $1(2.56)$ \\
\hline $16-17$ years & - & $\begin{array}{c}5 \\
(12.82)\end{array}$ & $\begin{array}{c}13 \\
(33.33)\end{array}$ & $\begin{array}{c}8 \\
(20.51)\end{array}$ & $\begin{array}{c}4 \\
(10.25)\end{array}$ \\
\hline
\end{tabular}

\section{DISCUSSIONS}

Teenage pregnancy should be viewed as a global phenomenon, with some differences in cultural or geographic areas, but with important health and social implications. According to UNICEF data on the state of the world in 2013, there were an estimated 13 million children born to mothers under 19 years. In Romania, according to the National Statistics Institute during 2009-2012, about 90,000 girls aged 12-18 years old gave birth (11).
The incidence of preterm newborn and those with low weight for gestational age is higher in those from teenage mothers and especially those aged under 16 compared with adult mothers. In a joint retrospective study in the United States, during the period 1995-2000, it stood out that the highest risk of newborn with VLBW, LBW or SGA had mothers aged under 18 compared to the group of mothers aged 20 to 24 years (2).

In our study, the highest share were premature babies of mothers aged 16 to 17 years, but infants with ELBW and VLBW came more frequently in the group of mothers of 13-15 years. While their number was lower than the group of newborn to mothers aged 16 to 17 years, due to the age of gestation and low birth weight, the newborn complications were more severe, requiring a long period of hospitalization and expensive laborious medical techniques.

Neonatal mortality rate is three times soared in newborn babies with mothers under 16 years old, compared with adult mothers $(6,7)$. A "Save the Children" organization report - State of the World's Mother from 2004 shows the consequences of the appearance of a child in adolescence and the risks associated, both during pregnancy and perinatal period. Children under one year old, born to teenage mothers, have a mortality risk 50 times higher than children born to mothers aged over 20 years (10). In our study, none of the patients died in the neonatal or postnatal period. Neuro-somatic disabilities, protein-caloric malnutrition and anemia are late complications that most of the patients in the studied group have developed, being predictor factors for morbidity and mortality in infancy and toddler periods.

Risk factors of medical/biological and socioeconomic type aimed at teenage mother, responsible for complications during pregnancy or postpartum, in adolescents aged 12-15 years are more related to immature physical development-underdeveloped pelvis with difficulties at birth, malnutrition and other medical factors. In adolescents of higher age, risk factors are more of socio-economic nature than biological (1). Due to incomplete data on possible maternal risk factors, a correlation between these and the complications associated with our patients could not be made. The only risk factor which was taken into account was the degree of hospitalization of pregnancy. Various studies show that a third of pregnant adolescents receive insufficient parenteral care, either delayed or directly during birth (3). 


\section{CONCLUSIONS}

Pregnant teenage girls have a much higher risk of premature birth and especially premature infants with low and very low weight for their gestational age, and in order to ensure the survival of these children, an increased amount of human and financial resources is needed. Postpartum complications are severe, with reserved long-term prognosis.

\section{REFERENCES}

1. Khashan A.S., Baker P.N., Kenny L.C. Preterm Birth and Reduced Birthweight in First and Second Teenage Pregnancies: A Register - based Cohort Study. BMC Pregnancy Childbirth 2010; 10:33

2. Xi-Kuan Chen; Flaming N., Demissie K. et al. Teenage Pregnancy and Adverse Bitrh Outcomes: A Large Population Based Retrospective Cohort Study. International Journal of Epidemiolgy. 2007; 36 (2): 368-373.

3. Radulescu L. Munteanu O., Radulescu M.I. et al. Implictii si consecinte ale sarcinii la adolescente. Revista Ginecologia.ro 4(2/2014): 6-11.

4. Gilbert W., Nesbitt T., Danielsen B. The cost of prematurity: Quantification by Gestational Age and Birth Weight. Obstretics and Gynecology (2003). 102 (3):488- 496.

5. Schuyler Center for Analysis and Advocacy: Teenage Births: Outcomes for Young Parents and their Children. December 2008. (www.scaany.org).

6. Broecker D., Hillard J.P. Pregnancy in Adolescence. Glob. libr. Women's med., (ISSN: 1756-2228) 2009.

7. McAnarney E. Adolescent pregnancy and its consequences. JMA 1989; 262:78.

8. Phippa M., Blume J., D.E. Monner S.M. Young maternal age associated with increased risk of postneonatal death. Obstetrics and Ginocology 2002; 100: 481-486.

9. Multeacu F. Sarcina la adolescente si riscurile asociate. Revista Medicala Romana 2007; Vol. LIV, nr. 4:202-203.

10.Ghitiu M.E, Roth M. Mituri si realitati legate de maternitate la varsta adolescentei.

11. Oprea M. Social Implication Of Parentality in Teenagers. GIDNI, Section - Psyhology and Sociology 2014; 107-117.

12.Boia M. Cresterea si dezvolatrea postnatala. Notiuni de Puericultura. Timisoara: Editura Victor Babes 2010: 39-41. 